\title{
A REVIEW OF HAEMORRHOIDS ACCORDING TO UNANI AND MODERN SYSTEM OF MEDICINE
}

\author{
Shama Parveen ${ }^{1}$, Shaikh Sufiya Bano ${ }^{2}$, Akhtar Hussain Chaudhury ${ }^{3}$ and Manzoor Ahmed ${ }^{4}$ \\ Department of Ilmul-Jarahat \\ Z.V.M. Unani Medical College \& Hospital, Pune, Maharashtra
}

\section{Review Paper}

\begin{abstract}
Haemorrhoids are variceal Dilatation of anal and perianal venous plexus. Classically situated in the 3,7,11, o'clock position (left lateral, right posterior \& right anterior respectively). Superior haemorrhoidal (vein) gives 2 branches on right side and 1 branch on left side. Hence, Piles are 2 on the right side and 1 on the left side. It was probably Buqrat (Hippocrates) (460 BC) who was the first to apply the name to the flow of blood from the veins of the anus. There is a detailed description of Bawaseer in classical books authored by ancient Unani physicians. Haemorrhoids are one of the most common anorectal disorders with a reported prevalence of $4.4 \%$ up to $36.4 \%$ of the general population. The peak prevalence occurs between 45 and 65 years of age. Anatomical classification of haemorrhoids includes internal and external haemorrhoids based on whether they are above or below the dentate line. Goligher's classification is the clinical staging of the prolapsing degree of internal haemorrhoids. Risk factors for hemorrhoidal disease are conditions associated with increased intra-abdominal pressures such as pregnancy, obesity, constipation and straining during defecation and sitting for a long time on the toilet seat, and chronic cough. Principal complaints of haemorrhoids include bleeding on defecation and prolapse of tissue. Haemorrhoid diagnosis involves taking a detailed history and conducting anorectal examinations (visual inspection, manipulation, digital examination, and anoscope. Report of first recorded treatment for haemorrhoids comes from the Egyptian papyrus dated 1700 BC: “... Thou shouldest give a recipe, an ointment of great protection; Acacia leaves, ground, titurated and cooked together. Conservative treatment is used in "Everyday Lifestyle Guidance. Drug therapy for haemorrhoids is typically utilized for bleeding, pain, and swelling. Operative hemorrhoidectomies are reserved mainly for third- and fourth-degree haemorrhoids.
\end{abstract}

No. of Pages: 9

References: 64

Keywords: Haemorrhoids, Review literature, Prevalence, Etiology, Classifications, line of treatment.

\section{INTRODUCTION}

Haemorrhoids are variceal Dilatation of anal and perianal venous plexus.(1) Classically situated in the 3,7,11, o'clock position (left lateral, right posterior \& right anterior respectively).(2) Superior haemorrhoidal (vein) gives 2 branches on right side and 1 branch on left side. Hence, Piles are 2 on right side and 1 on left side.(2) It is an abnormal downwards sliding of anal cushions due to straining or other causes. Anal cushions are aggregation of blood vessels (arterioles, venules), smooth muscles and elastic connective tissue in the submucosa that normally reside in left lateral, right posterolateral and right anterolateral anal canal.(3) Piles can be mucosal or vascular. Vascular type is seen in young; mucosal is seen in old patients. Present concept is weakening of Park's ligament which is the lower end of the external sphincter.(3) Bawaseer is excessive growth or development

*Corresponding author: shamaparveen0106@gmail.com 
of masses at the opening of vessels of the rectum or around the anus and characterized by symptoms like bleeding, pain and prolapse.(4) The word "Haemorrhoid" is derived from the Greek word "Haema" meaning blood, and "Rhoos" meaning flowing, and was originally used by Buqrat (Hippocrates) to describe the flow of blood from the veins of the anus. (5)

\section{REVIEW LITERATURE}

It was probably Buqrat (Hippocrates) (460BC) who was the first to apply the name to the flow of blood from the veins of the anus.(5) There is a detailed description of Bawaseer in classical books authored by ancient Unani physicians. Buqrat (Hippocrates) (460-377BC) described Bawaseer that it is the varicosities of internal mucus membrane of rectum in which the vein gets swollen similar to the vein of lower limb.(6) The common man's term.

"Piles" is derived from latin word "Pila" meaning a ball.(7) According to Unani physicians, the development of Bawaseer is attributed mainly to saudavi and viscous blood. Saudavi blood is produced mainly due to the consumption of saudavi, spicy and hot substances and drugs which are hot in temperament. While Safra, when mixed with blood, warms the blood and blood becomes burn and viscous/thick. $(8,9,10,11,12,13)$ Jaleenoos (Galen) (129-200 AD) also gives a good clinical description of haemorrhoids. He states that anorectal disorders are very difficult to treat as the rectum and anus are highly innervated and sensitive and are the permanent route for the passage of stool.(14) The Indian Susruta (4th -5th century AD), describes haemorrhoids and its treatment procedures comparable to those in the Hippocratic treatise, but with advancement in surgical procedures and emphasis on wound cleanliness. The use of clamp and cautery is also described in Susruta Samhita. $(5,15)$ In the past many great personalities have suffered from haemorrhoids, like Napoleon Bonaparte, George Brett (Hall of fame baseball player), and Don Juan Demoranna. Napoleon Bonaparte lost his battle of waterloo because of the delay in launching the attack due to a bad attack of bleeding haemorrhoids.(16) Tabari (d.985AD) also described Bawaseer as saudavi disease which is due to the fassad (Derangement) in blood and increased viscosity of blood. (17) Akbar Arzani (d.1722AD) the author of Tibb-e-Akbar, while writing about the causes of Bawaseer says that thick blood uses of produce over growths on the heads of anal blood vessels.(18) According to Samarqandi (d.1222AD) Bawaseer is the warty swelling at the end of rectal veins due to viscid Saudavi Khoon (Melancholic Blood).(6) According to Al-Maseehi (d.1010 AD) Formation of extra growth around or in anal called as Bawaseer.(19) Ali Ibn Abbas Majoosi (930-994 AD) also considered the deranged production of humours as the basis cause of Bawaseer. He says that such diseases are developed due to excessive production of saudavi khoon (Melancholic blood) from the liver.8
According to Abu Marwan Ibne Zuhar,Bawaseer is the growth or swelling at the end of the vessels of the rectum.(20) Ibn Sina (980-1037AD) in Al-Qanoon Fil-Tibb says that Bawaseer are usually produce due to accumulation of sauda (Black Bile) or saudavi khoon (Melancholic blood); less commonly it may developed as a result of Balgham (Phlegum).(13)

\section{GENERAL INCIDENCE AND PREVALENCE OF HAEMORRHOIDS}

Haemorrhoids are one of the most common anorectal disorders with a reported prevalence of $4.4 \%$ up to $36.4 \%$ of the general population. The peak prevalence occurs between 45 and 65 years of age. Approximately one-third of patients affected by haemorrhoids seek medical advise. Different studies showed that about 5\%-10\% of patients suffering from haemorrhoids do not respond to conservative treatments, so surgical procedures become the treatment of choice in such cases.(21) In India approximately 40,723,288 people are reported to have haemorrhoids. One million new cases are reported annually, at the rate of 47 per 1000 and this rate increases with age. Current statistics suggest nearly half of the world's population will experience some form of haemorrhoids especially when they reach the golden age of fifty.(22) A higher prevalence is reported in specific groups, such as pregnant or postpartum women, in whom the prevalence of hemorrhoidal disease is between 12 and $41 \% .(23,24)$ Hemorrhoidal disease is one of the most common anorectal conditions seen in general practice. But the true prevalence in the general population is not well understood, partly because many patients do not seek treatment. $(25,26)$ According to NIH data, nearly 1 million cases are reported annually in the US at the prevalence rate of $4.4 \%$. It is estimated that $58 \%$ of people aged over 40 years have the disease in the US. Some researchers suggest that about $75 \%$ of people will have symptomatic haemorrhoids at some point of time in their lives. $(27,28)$

\section{CLASSIFICATION OF HAEMORRHOIDS: Classification as per Unani System of Medicine: $(8,9,10,11,12,13,29,30,31,32,33,34)$}

Unani scholars have classified Bawaseer in Various ways, which are as follows;

[1] According to Ibn-e-Sina

[a] According to shape

Sululi (wart like)

Inabi (Grapes like)

Tooti (Mulberry like)

[b] According to Haemorrhage:

Mun Fatiha (which bleeds)

Umiya (which does not bleed)

[c] According to Location:

Nabita (External)

Ghaira (Internal)

[2] According to Azam Khan:

Sululi 
Inabi

Tooti

Nafakhi

Nakhli

Tabni

Tamari

[3] According to Ajmal Khan:

Bawaseer-e-Khooni (Damwi)

Bawaseer-e-Reehi (Badi)

[4] As per shape and appearance of piles masses:

1. Sululi (Adasiya or Hamasiya): This variety of the pile masses is like lentil or gram in its size and texture.

2. Inabi: This variety piles masses like grapes. They are either round or flat in shape and red or purple in colour.

3. Tooti: This variety of pile masses are like mulberry. They are soft in consistency and long in shape. They are round and red in colour at their tops whereas their roots are thin and green in colour.

4. Nafakhi: This variety of pile masses is like bubbles and white in colour, they do not produce any pain in such.

5. Nakhli: This variety of pile masses resemble the root of the date tree, which contain multiple branches and fibers.

6. Teeni: This type of pile masses are round and flat and look like figs. This is a painful variety of Bawaseer.

7. Tamari: These types of pile masses are rough and hard like dry dates. It also causes pain.

[5] As per the bleeding tendency of pile masses:

On the basis of bleeding tendency Unani scholars have described two type of Bawaseer.

1. Bawaseer Munfaitha: This type is also known as Bawaseer Khooni. In this type there is bleeding.

2. Bawaseer Umaiya: This type is also known as Bawseer-e-Reehi. In this type three is no bleeding.

[6] As per location of piles masses:

As per the location, Bawaseer are classified in two type-

1. Bawaseer Nabita: In this type, the pile masses are located in the outer part of the anal canal and this is also known as external piles.

2. Bawaseer Ghaiyera: In this type, pile masses is situated in the inner part of anal canal and this is also known as internal piles.

\section{CLASSIFICATION AS PER MODERN SYSTEM OF MEDICINE:}

Clinical classification of haemorrhoid:

Anatomical classification of haemorrhoids includes internal and external haemorrhoids based on whether they are above or below the dentate line.

As a clinical measurement, Goligher's classification,35 which is calculated in four grades based on prolapsing and reduction, is most widely utilized.(36)

Goligher's classification is the clinical staging of the prolapsing degree of internal haemorrhoids. Internal haemorrhoid grade classification (including Goligher's classification) is used universally for choosing a course of treatment. $(37,38)$

Grade I: Haemorrhoids are visualized on anoscopy and may bulge into the lumen but do not prolapse below the dentate line.

Grade II: Haemorrhoids prolapse out of the anal canal with defecation or straining but reduce spontaneously.

Grade III: Haemorrhoids prolapse out of the anal canal with defecation or straining and require manual reduction.

Grade IV: Haemorrhoids are irreducible and may strangulate.

Colonoscopic classification, including circumferential degree, size, and red colour sign, is well correlated with bleeding symptoms and is useful for treatment evaluation.39 Vascular and mucosal types can be broadly categorized through anoscopic inspection alone.(40) However, this type of classification with clear definition is not standard.

\section{ETIOLOGICAL FACTOR}

Bowel habits and lifestyles can be risk factors for haemorrhoids. However, the involvement of genetic factors is unknown. Risk factors for hemorrhoidal disease are conditions associated with increased intra-abdominal pressures such as pregnancy, obesity, constipation and straining during defecation and sitting for a long time on the toilet seat, and chronic cough. cough. $(41,42)$

\section{In Unani System of Medicine:}

Hakim Kabiruddin (1894-1976 AD) has quoted Hippocrates in his book Tarjuma-e-Kabir as under haemorrhoids are the vascular tumours of mucous membranes of the lower rectum. He further says that veins of lower part of rectum and anal canal are as swollen as in varicosity of veins. Hakim kabiruddin has described following factor as additional cause/ predisposing factors for haemorrhoids.(10,29).

1. Repeated pressure on the veins of anus

2. Habitual constipation

3. Passage of dried hard stool

4. Sedentary habit

5. Abstinence from physical labour and exercise

6. Excessive use of meat, red chilies and spices

7. Excessive alcoholism

8. Repeated use of potent purgatives 
9. Weakness in the functioning of liver

10. Pressure of uterus during pregnancy

Hakim Ajmal khan (1864-1927 AD), described the following causes of haemorrhoid in kitabul

Haziq. $(29,30)$

1. Excessive heat

2. Hot climatic condition of India

3. Excessive use of meat and red chilies

4. Burning of blood leading to production of thick blood.

Hakim Wajid Ali Khan, the author of Shifaul Abdan mentions the following causes for haemorrhoids.(29)

1. Increased quantity of Safra in blood

2. Increased quantity of Sauda in blood

3. Excessive production of Balgham

Hakim Sharif Khan (1725-1807 AD), in Maftah-ul-Hikmat has also considered the sauda as the fundamental cause of haemorrhoids. He says that piles (Bawaseer) are the moles formed on the mouth of anal blood vessels. Further he has described the following etiological factors for the piles.(29)

1. Liver disease

2. Constipation

3. Splenic disease

4. Disorder liver function

5. Excessive intake of spicy food

6. Hot drugs and food

7. Abstinence from and food

8. Excessive intake of alcohol

9. Sedentary habits

10. Pregnancy

Hakim Alwi Khan (1669-1749 AD) described the following factors of piles in his book Khulasatul Majarib.(29)

1. Increased amount of Sauda in blood

2. Saudavi Mizaj (Melancholic temperament)

3. Dilatation of anal blood vessels.

4. Excessive Sauda makes the blood thick especially in Saudawi temperament people or because of any pressure anal blood vessels gets dilated.

\section{Misalliances}

1. According to Mohammad bin Zakariya razi haemorrhoids may also develop due to excessive consumption of Saudawi and sweet substances.(11)
2. According to some physicians, haemorrhoids may also develop in those persons who used to sit more in latrine, especially those latrines that are utilized by haemorrhoids patients. $(9,10,12)$

3. According to Ibn e Sina, haemorrhoids are also very common in southern areas, and commonly develop due to the continuous blowing of southern winds.(13)

\section{CLINICAL MANIFESTATIONS}

Principal complaints of haemorrhoids include bleeding on defecation and prolapse of tissue. Secondary symptoms may be associated with haemorrhoids but often arise from other causes that are unrelated.

Contrary to popular belief, pain is not a primary symptom and usually occurs as a results of complication of haemorrhoids. $(5,43)$

\section{Principal Symptoms}

\section{Bleeding}

Rectal bleeding is the most common symptom of haemorrhoids. Haemorrhoidal bleeding is bright red and painless. If there is pain, another diagnosis such as a fissure should be exclude. $(5,43)$

According to Jalinoos (129-200 AD) it is impossible that a patient has haemorrhoids and there is no bleeding. In Bawaseer liver sends viscous, foul and Saudawi blood towards rectum which leads to the hyperemia of the rectal vessels and this leads to the perforation of the vessels and ultimately bleeding. $(20,14)$

\section{Prolapse}

Prolapse is another common symptom of haemorrhoids. It occurs in larger haemorrhoids. Haemorrhoidal prolapse usually occurs at the time of defecation . It is usually painless and reduces spontaneously after defaecation in 2nd grade of haemorrhoids, in 3rd grade it requires manual reduction and 4 th grade haemorrhoids are trapped outside the anal canal and cannot be reduced by manual pressure. $(5,10,44)$

According to Mohammad Bin Zakariya Razi (850-923 AD), in this disease (Haemorrhoids), sometimes rectum prolapses externally and then remains in that condition. In the same context, he also states that, sometimes due to warame haar (inflammation) spasmodic condition develops in the rectum which results in the prolapse and swelling of the rectum.(13)

\section{Secondary Symptoms}

\section{Pain}

Pain is usually not a feature of haemorrhoids and should raise the possibility of another disease such as a fissure of abscess. 
Prolapsed haemorrhoids can cause a dragging sensation until they are reduced. Once the prolapse is reduced, the discomfort quickly resolves.(5,43,45)

According to Ismail Jurjani (12th cent AD, if there is burning and throbbing pain then it is due to Safrawi matter and along with pain if patient feels fatigue and restlessness then it is due to Ghaliz dam (viscid blood). In bleeding piles, if due to any reason, bleeding stops it causes severe pain and itching in the rectum.(12)

\section{Anal pruritus}

Mucus discharge can cause maceration and irritation of skin leading to pruritus. Mostly pruritis is secondary to other causes such as infection or dermatological conditions. $(5,43,45)$

\section{Mucus Discharge}

Mucus is produced by the secretory columnar epithelium above the dentate line. When the prolapse is significant enough to protrude through the anal canal, the columnar mucosa is exposed to the outside environment and becomes irritated, thus secretes mucus. $(5,43)$

\section{Faecal Incontinence}

Some patients with large prolapsed haemorrhoids may complain of minor faecal incontinence. The large chronically prolapsed haemorrhoids may cause incomplete closure of the anal canal and predispose to the leakage of mucus and faeces.(5)

In Bawaseer reehi there are bowel sounds due to riyadh which can be heard over the umbilicus and this riyah may descends towards penis, scrotum or coccygeal region (in males) or it may ascends towards chest ribs, neck or shoulders. This riyadh may leads to body and joints pain, loose motions or it may cause constipation indigestion and loss of appetite.(12)

\section{Anaemia}

Rarely anaemia can be caused by bleeding haemorrhoids so this can be called as a complication rather than a symptom. $(5,43,45)$

According to Mohammad Bin Zakariya Razi (850-923 AD), when there is excessive bleeding, the patient appears pale and whitish due the dominance of Balghami and Safrawi Matter.(11)

\section{USEFUL DIAGNOSTIC METHODS FOR HAEMORRHOIDS}

Haemorrhoid diagnosis involves taking a detailed history and conducting an anorectal examinations (visual inspection, manipulation, digital examination, and anoscope.(46) It is impossible to confirm the diagnosis of haemorrhoids with a digital examination alone;(47) therefore, an anoscope (or proctoscope) is utilized for diagnostic purposes.48
In cases where complaints of prolapsing symptoms are inconsistent with the findings, straining testing in the toilet is useful.(46,47) Even when haemorrhoids are confirmed, when melena or bloody stool is discovered, a colonoscopy should be performed to rule out other diseases.(49)

\section{DIFFERENTIAL DIAGNOSIS}

Differential diagnosis of haemorrhoids includes anal skin tags, fibrous anal polyp, peri-anal hematoma, rectal prolapse, anal fissure, dermatitis and rectal tumour, intersphincteric abscess melanoma, carcinoma.(50)

\section{USOOL ILAJ (LINE OF TREATMENT):}

$(8,9,10,13,31,33,51,52,53,54,55)$

Jalinoos (129-200 AD) stated that anal diseases are difficult to treat as anus is a natural route for expulsion of waste material and is highly sensitive to local changes.

The line of treatment for Bawaseer in Unani system of medicine the ancient Unani physicians described in detail as,

- Treat the main cause.

- Tanquia mawad (Diversion of morbid humor)

- Advice light and easily digestible food.

- Avoid food which produces Sauda.

- Advice light exercise example walking etc.

- Avoid sitting on hard and cold places.

- Clean anal region with hot water after defaecation.

- Avoid constipation.

- Don`t stop bleeding directly until the patient becomes weak.

- Fasad (Venesection) of Reg-e-Saphin (cephalic Vein).

- Taliq (leech) application on the mass of the Bawaseer (haemorrhoid).

- Hijama (Cupping) application in between buttock regions.

- Use of Akkal advia (corrosive medicine) to burn the haemorrhoidal mass.

- Use Mussakin advia (analgesic) in the form of Dhoni, Zimad, Nutool.

- External use of Mundamil qurooh advia (Cicatrizant Medicine).

Mushil-e-Sauda (Melanagogue), Muqawwi Meda wa Ama (Tonic for stomach and intestine), Mohallil Awram (Antiinflammatory), Musakkin (Analgesic), Habis-e-Dam (Haemostatic), Mundamil-e-Zakham (Cicatrizant), Mufatehat (Deobstruent), mulaiyyanat (Laxative) Adviya.

Report of first recorded treatment for haemorrhoids comes from the Egyptian papyrus dated 1700 BC: “... 
Thou shouldest give a recipe, an ointment of great protection; Acacia leaves, ground, titurated and cooked together. Smear a strip of fine linen there-with and place in the anus, that he recovers immediately.(56)

Hippocrates in 460 BC wrote of haemorrhoids treatment similar to today's rubber band ligation procedure thus: “And haemorrhoids in like manner you may treat by transfixing them with a needle and tying them with very thick and woolen thread, for application, and do not ferment until they drop off, and always leave one behind; and when the patient recovers, let him be put on a course of Hellebore.(56)

A Roman physician named Celcus (25 BC - ad 14) described the ligation and excision surgeries, The Indian Susruta Samhita, an ancient Sanskrit text dated between the fourth and fifth century ad, described treatment procedures comparable to those in the Hippocratic treatise, but with advancement in surgical procedures and emphasis on wound cleanliness.(56)

\section{MANAGEMENT OF HAEMORRHOIDS:} Management of Bawaseer in Unani System of Medicine: In general practice the Unani physicians used to manage the cause of Bawaseer by two methods.

1. Local Treatment

2. Systemic Treatment

1. Local Treatment: $(8,48,53,54,55)$

The treatment is very simple if pile masses are not inflamed. In any way constipation is to be avoided and local aseptic condition is to be maintained. Sometime application of Marham/Qairooti, Zimad over the pile masses is advised. Every effort is made to protect the pile masses from pressure and erosion.

If Bawaseer are inflamed and thrombosed, complete bed rest is advised. Hot fomentations apply on pile masses and the bowel is kept clean with the help of enema. A number of methods and drugs for hot fomentation to reduce.

The inflammation and severity of pain are available in Unani system of medicine e.g. Roghan-e-Gul, Aab-e-Mako-e-Sabz, Safeda Kashghari, Maghz-e-Neem, Muqil (Guggul), Rasaut etc.

\section{Systemic Treatment:}

General treatment to Bawaseer patients is offered by four methods of treatment in Unani system:
a) Ilaj-Bil-Ghiza (Dietotherapy)
b) Ilaj-Bil-Tadbeer (Regimental therapy)
c) Ilaj-Bil-Dawa (Drug therapy)
d) Ilaj-Bil-Yad (Surgery)

\section{TREATMENT OF HAEMORRHOIDS IN MORDEN SYSTEM OF MEDICINE}

1) Conservative treatment is used in "Everyday Lifestyle Guidance.

2) Drug therapy for haemorrhoids is typically utilized for bleeding, pain, and swelling.

3) None of the oral medications is approved for use during pregnancy, but some analgesic ointments and suppositories may be utilized.

\section{1) Everyday Lifestyle Guidance}

The guidance given for the patient's everyday lifestyle (improvement of lifestyle habits) suggests taking care when sitting for long periods of time, working at cold temperatures, straining during defecation, choosing what to eat and drink, becoming physically exhausted, and enduring emotional stress. Patients are instructed to avoid letting their bodies get too cold, and women are encouraged to be especially careful during their menstrual cycles. In terms of food and drink, patients are told to be sure to get enough water, increase the amount of fiber in their diets(57), and be careful with their alcohol consumption. As to their toilet habits, patients are instructed to avoid excessive straining and extended time defecating (sitting on the toilet for long periods).

Patients are told not to hold it and to finish defecating in as short a time as possible.(58) When localized blood flow impairment occurs together with haemorrhoids, taking warm baths (sitz baths) is effective.

\section{2) Drug treatment}

Drug treatment has a recognized effect in relieving pain and reducing swelling; however, these medications have no efficacy with prolapsed haemorrhoids. In terms of medication, there are both oral and topical treatments, such as suppositories and ointments. Ointments are used for lesions below the dentate line, while suppositories are used for lesions above the dentate line. Steroidal medications have a higher efficacy when patients present with swelling, pain, and heavy bleeding associated with acute inflammation. In rare cases, when steroidal dermatitis or perianal candidiasis occurs, long-term use of steroids should be avoided.(58)

Tribenoside or bromelain are effective for inflammatory edema;(59) local anesthetic agents are effective for pain; and bismuth-based agents are effective for bleeding. There are some reports from abroad indicating that pain, swelling, and bleeding can be addressed with flavonoids.(60,61).

\section{3) Drug therapy and pregnancy:}

As drug therapy for pregnant women can have an adverse effect on the unborn child, careful consideration must be given to its administration. To prevent unnecessary risks, including premature contractions, spontaneous abortion, and birth defects, etc., excessive use of medication should be 
avoided.(62) There have been no reports of birth defects among haemorrhoid patients using ointments/suppositories.

There have been issues with cleft palate developing in animal foetus when the mother has undergone long-term hydrocortisone treatment. Consequently, long-term use of steroidal ointments/suppositories is contraindicated.(63)

The use of flavonoids in pregnant women has not been sufficiently evaluated; however, there is one case report of a fetal death and one of a birth defect, indicating that this treatment may not be completely safe.(64)

\section{Nonoperative (conservative) options:}

Rubber band ligation, sclerotherapy, infrared photocoagulation, cryotherapy, manual anal dilatation, LASER haemorrhoidectomy, the harmonic ultrasonic scalpel haemorrhoidectomy, Doppler guided hemorrhoidal artery ligation, and the new atomizing technique that uses the atomizer wand to excise and vaporize haemorrhoids.

Most nonoperative procedures are reserved for first-and second-degree haemorrhoids and are usually carried out on an outpatient basis.

\section{Operative options:}

The clamp and cautery haemorrhoidectomy, open haemorrhoidectomy, closed haemorrhoidectomy, submucosal haemorrhoidectomy, whitehead circumferential haemorrhoidectomy, stapled haemorrhoidectomy, radiofrequency ablation and suture fixation haemorrhoidectomy, pile suture' method, the bipolar diathermy haemorrhoidectomy, and the ligasure haemorrhoidectomy. Operative hemorrhoidectomies are reserved mainly for third- and fourth-degree haemorrhoids.

\section{CONCLUSION}

It was probably Buqrat (Hippocrates) (460BC) who was the first to apply the name to the flow of blood from the veins of the anus. There is a detailed description of Bawaseer in classical books authored by ancient Unani physicians. Haemorrhoids are one of the most common anorectal disorders with a reported prevalence of $4.4 \%$ up to $36.4 \%$ of the general population. The peak prevalence occurs between 45 and 65 years of age. Report of first recorded treatment for haemorrhoids comes from the Egyptian papyrus dated 1700 BC: “... Thou shouldest give a recipe, an ointment of great protection; Acacia leaves, ground, titurated and cooked together.

Conservative treatment is used in "Everyday Lifestyle Guidance. Drug therapy for haemorrhoids is typically utilized for bleeding, pain, and swelling. Operative hemorrhoidectomies are reserved mainly for third-and fourth-degree haemorrhoids.

\section{REFERENCE}

1. Vinay Kumar, Abul K, Nelson Fausto, Pathologic basis of disease 7th edition, pp.854.

2. Manipal manual of surgery. pp 793.

3. Sriram Bhat M.SRB'S manual surgery 4th edition. New Delhi: Jaypee brother medical publication, pp.10381042.

4. Majoosi, A.I.A. (2010) Kamil al sinaa'at (Urdu Translation by Kantoori), New Delhi: Idara kitab-ulShifa. Pp.516-518.

5. Mtra et.al. Role of piloherb tablets and ointment in the treatment of haemorrhoids, World Journal of Pharmacy and pharmaceutical sciences,2015; Vol. 4, Issue 08.PP 1640-1647.

6. Kabeeruddin M. Molejat Shareh Asbab (Tarjuma Kabir). Vol.2, New Delhi: Eijaz Publishing house.2012. PP 634-638.

7. Gami Bharat. Haemorrhoids-a common ailment among adults, causes \& treatment: A review. International Journal of Pharmacy and Pharmaceutical Sciences. 2011: 3(suppl 5): 5-12.

8. Mjoosi A I A. Kamil al sinaa'at (Urdu Translation Kantoor). New Delhi: Idara kitab-ul-Shifa; 2010. PP 516-518.

9. Azam KM. Ikseere Azam (Urdu Translation By Mohammed Kabeeruddin): 2010.PP 661-673.

10. Kirmani NBA. Sharah Asbab (Tarjuma Kabir). Vol. 2, New Delhi: Eijaz Publishing house.2012. PP 634-638.

11. Razi A.B. Kitab Ul Havi. Vol.11. New Delhi: CCRUM. 2004. PP 28-43.

12. Jurjani A.H. Zakheera Khawarazam Shahi (Urdu Translation By Hadi Husain). New Delhi: Idara Kitab-ulShifa; 2010. PP 461-463.

13. Ibn Sina. Al Qanoon-fil-Tibb (Translation by Kantoori). Vol.3. New Delhi: Eijaz Publishing House; 2010. PP 985986.

14. Qamri AMH. Gana Mana. New Delhi: CCRUM. 2008. PP 322.

15. Form Cleopatra to Obama: A look at Hemorrhoid History (Internet) cited on 5 september 2014. Available from http://gracethomas. hubpage.com/hub/From-Cleopatrato-Obama.

16. Burkitt DP, Graham-Stewat CW. Haemorrhoidpostulated pathogenesis and proposed prevention: Postgraduate Medical Journal. 1975:51. PP 631-636.

17. Tabari ABR. Moalajah Buqratiya. Vol.2. New Delhi: CCRUM; 1997. PP 392. 
18. Arzani A. Tibb-e-Akbar (Urdu Translation Mohd Husain). Deoband: Faisal Publications. PP 507.

19. Masseehi A A. Kitab-al-Umda-fi-Jarahat. Vol.2. New Delhi: CCRUM. Publish No. 35. PP 251.

20. Ibne Zuhar Abu Marwan Abdul Malik. Kitabut Taiseer fil Madawa Wat Tadbeer. New Delhi: CCRUM; 1986. PP 152.

21. Sakr M, Saed K. Recent advances in the management of haemorrhoids. Word J Surg Proced 2014; 4 (3): 5556Availablefrom:URL:http://www.wjgnet.com/221928 32/full/v4/i3/55.htmDOI:http:/dx.doi.org/10.5412/wjsp .v4.i3.55.

22. Statistics by country for Hemorrhoids [internet] cited on 24 June 2014. Available from http:// www.rightdiagnosis.com /h/ hemorrhoids/statecountry.htm

23. Mao L, Ma L, Liu N et al. Self-reported health problems related to traditional dietary practices in postpartum women from urban, suburban and rural areas of Hubei province, China: the 'zuo yuezi'. Asia Pac. J. Clin. Nutr. 25(1), 158-164(2016).

24. Poskus T., Buzinskiene D., Drasutiene G. et al. Haemorrhoids and anal fissures during pregnancy and after childbirth: a prospective cohort study. BJOG. 121(13), 1666-1671 (2014).

25. Tournu G., Abramowitz L., Couffignal C. et al. Prevalence of anal symptoms in general practice: a prospective study. BMC Fam. Pract. 18(1), 78 (2017). 26. Abramowitz L, Benabderrahmane M, Postpaid, Philip J, Laouenan C. The prevalence of proctological symptoms amongst patients who see general practitioners in France. Eur. J. Gen. Pract. 20(4), 301-306 (2014).

27. Fundukian L.J. Hemorrhoids. Chapter in: The Gale Encyclopedia of Alternative Medicine. 3rd edition. Detroit: Gale; 2009:1032.

28. Johanson J.F., Sonnenberg A. The prevalence of hemorrhoids and chronic constipation, an epidemiologic study. Gastroenterology. 1990; 98 (2): PP 380-6.

29. Yasmeen S, Rais-ur-Rahman. Understanding and management of haemorrhoid in the perspective of Unani system of medicine. Indian Journal of Unani Medicine. Vol.5. 2012. PP153-159.

30. Ajmal K. Haaziq. Delhi. Hindustani Dawakhana 1997. PP 254-255.

31. Multani HC. Tazulhikmat. Lahore: Malik Book depo. PP 215-222.

32. Gulam Jilani. Makhzan Ul Ilaj. New Delhi: Idara Kitabus-Shifa. 2005. PP 564-569.
33. Qureshi MH. Jam-ul-Hikmat. New Delhi:Idara Kitaus-Shifa. 2011. PP 786-793.

34. Khan MS. Rehbar Moalejat. New Delhi:Idara Kita-usShifa. 2009. PP 177-118.

35. Goligher JC. Surgery of the anus, rectum and colon. 5th ed. London: Billiere Tindall; 1984: 101 p.

36. Kurokawa A, Kitsuki K, Shimotani S. [Classification of hemorrhoids]. Rinsho Geka. 2008; 63(11): 81-7. Japanese.

37. Banov L. Jr, Knoepp L.F. Jr, Erdman L.H., et al. Management of hemorrhoidal disease. J S C Med Assoc. 1985 Jul; 81(7): 398401.

38. Madoff R.D., Fleshman J.W. American Gastroenterological Association technical review on the diagnosis and treatment of hemorrhoids. Gastroenterology. 2004 May 31; 126(5): 1463-73.

39. Fukuda A., Kajiyama T., Kishimoto H., et al. Colonoscopic classification of internal hemorrhoids: usefulness in endoscopic band ligation. J Gastroenterol Hepatol. 2005 Jan 1; 20(1): 46-50.

40. Graham-Stewart CW. What causes hemorrhoids? A new theory of etiology. Dis Colon Rectum. 1963 Sep 1; 6: 333-44.

41. Caglayan M., Turkoglu A., Oktayoglu P. et al. Evaluation of the incidence of haemorrhoidal disease in patients with ankylosing spondylitis. Clin. Rheumatol. 34(3), 511-514(2015).

42. Ravindranath GG, Rahul BG. Prevalence and risk factors of hemorrhoids: a study in a semi-urban centre. Int.J. Surg. 5(2), 496-499(2018).

43. Russell RCG, William SN, Bulstrode CJK, ED, Bailey and love;s short practice of surgery, 25th edition :Arnold Publication;2010: PP 1115-34.

44. Sriram, Bhat M. SRB's Manual of Surgery. 3rd edition. New Delhi:Jaypee Brothers Medical Publication. 2010. PP 905-907.

45. Khan RM. Prevalence of Hemorrhoid among the Patient Visiting NIUM. Dissertation Submitted for M.D (Tahaffuzi-wa-Samaji-Tib) in the Dept. of Tahaffuzi-waSamaji Tib. 2013. NIUM to RGUHS, Bangalore, Karnataka.

46. Matuda Y, Asano M. [Examination methods and technical points of anal diseases]. Geka. 2011; 73(9): 913-8. Japanese.

47. Iwadare J. Basic [Outpatient examination of anorectal disorders]. Itochu. 2003; 38(9): 1225-37. Japanese.

48. Patient Care Committee of The Society for Surgery of the Alimentary Tract (SSAT). Surgical management of hemorrhoids. J Gastrointest Surg. 2005; 9(3): 455-6. 
49. Levin B, Lieberman D.A,. McFarland B., et al. Screening and surveillance for the early detection of colorectal cancer and adenomatous polyps, 2008: a joint guideline from the American Cancer Society, the US Multi-Society Task Force on Colorectal Cancer, and the American College of Radiology. Gastroenterology. 2008 May 1; 134(5): 1570-95.

50. Khan RM. et.al. A comprehensive review of haemorrhoids with Unani (greeco-arabic) and modern description. Internal Journal of basic Medicine and Clinical research, Vol.1, Issue 3: 2004. PP 52-65.

51. Tabri ABR. Firdus-ul-Hikmat (Translation by Mohammed Awwal Shah Sambhali). New Delhi: Idara Kitab-us-Shifa. 2010. PP 252-253.

52. Razi AB. Kitab-al-Mansoori. New Delhi: CCRUM. 1991. PP 100-102,382-383.

53. Samarqandi N. Sarah Asbab (Translation by Kabeeruddin). New Delhi: Idara Kitabul-ul-Shifa. 2009. PP 530-535.

54. Hamdani KH. Usool-e-Tib,Aligarh: Lithu Colour Printers. 1980. PP 549.

55. Chandpuri K. Mauzazul Qanoon. New Delhi: Taraqqi Urdu Bureau. 2000. PP 353.

56. Ellesmore S., Windsor AC. Surgical History of Hemorrhoids. In: Charles MV, editor. Surgical Treatment of Haemorrhoids. London: Springer; 2002. p. 1-4.
57. Cataldo P, Ellis N, Gregorcyk S, et al. Practice Parameters for the Management of Hemorrhoids (Revised). Dis Colon Rectum. 2005; 48: 189-194.

58. Chikuba A. [Conservative treatment of hemorrhoids]. Geka Chiryo. 2011; 105: 17-22. Japanese.

59. Kinugasa A, Ishiyama Y, Nishio A, et al. [Clinical effects of bromelain preparations for hemorrhoids: a double-blind, comparison study]. Shinyaku To Rinsho. 2000; 49: 1240-58. Japanese.

60. Di Pierro F, Spinelli G, Monsu G, et al. Clinical effectiveness of a highly standardized and bioavailable mixture of flavonoids and triterpenes in the management of acute hemorrhoidal crisis. Acta Biomed. 2011 Sep 1; 82(1): 35-40.

61. Jiang ZM, Cao JD. The impact of micronized purified flavonoid fraction on the treatment of acute haemorrhoidal episodes. Curr Med Res Opin. 2006 Jun 1; 22(6): 1141-47.

62. Sato T, Kano H, Hayashi M, et al. [Laxatives]. Jissen Ninpo Kusuri. Yakujisinposha. 1996;518-522. Japanese.

63. Sato T., Kano H., Hayashi M., et al. [Laxatives]. Jissen Ninpo Kusuri. Yakujisinposha. 1996;510-512. Japanese.

64. Quijano CE, Abalos E. Conservative management of symptomatic and/or complicated haemorrhoids in pregnancy and the puerperium. Cochrane Database Syst Rev. 2005 Jul; 20(3): CD 004077. 